\title{
Characterizing gas flow from aerosol particle injectors
}

Daniel A. Horke, Nils Roth, Lena Worbs, and Jochen Küpper

Citation: Journal of Applied Physics 121, 123106 (2017); doi: 10.1063/1.4978914

View online: http://dx.doi.org/10.1063/1.4978914

View Table of Contents: http://aip.scitation.org/toc/jap/121/12

Published by the American Institute of Physics

\section{Articles you may be interested in}

Carrier capture in InGaN/GaN quantum wells: Role of electron-electron scattering

Journal of Applied Physics 121, 123107123107 (2017); 10.1063/1.4979010

Enhanced electrical properties, color-tunable up-conversion luminescence, and temperature sensing behaviour in Er-doped Bi3Ti1.5W0.5O9 multifunctional ferroelectric ceramics

Journal of Applied Physics 121, 124102124102 (2017); 10.1063/1.4979096

Electric field measurement in the dielectric tube of helium atmospheric pressure plasma jet

Journal of Applied Physics 121, 123304123304 (2017); 10.1063/1.4979310

Wealth inequality: The physics basis

Journal of Applied Physics 121, 124903124903 (2017); 10.1063/1.4977962

Mass spectrometric investigations of plasma chemical reactions in a radiofrequency discharge with $\mathrm{Ar} / \mathrm{C} 2 \mathrm{H} 2$ and $\mathrm{Ar} / \mathrm{C} 2 \mathrm{H} 2 / \mathrm{O} 2$ gas mixtures

Journal of Applied Physics 121, 123303123303 (2017); 10.1063/1.4979021

Prediction of irradiation induced microstructures using a multiscale method coupling atomistic and phase field modeling: Application to the AgCu model alloy

Journal of Applied Physics 121, 125108125108 (2017); 10.1063/1.4978964

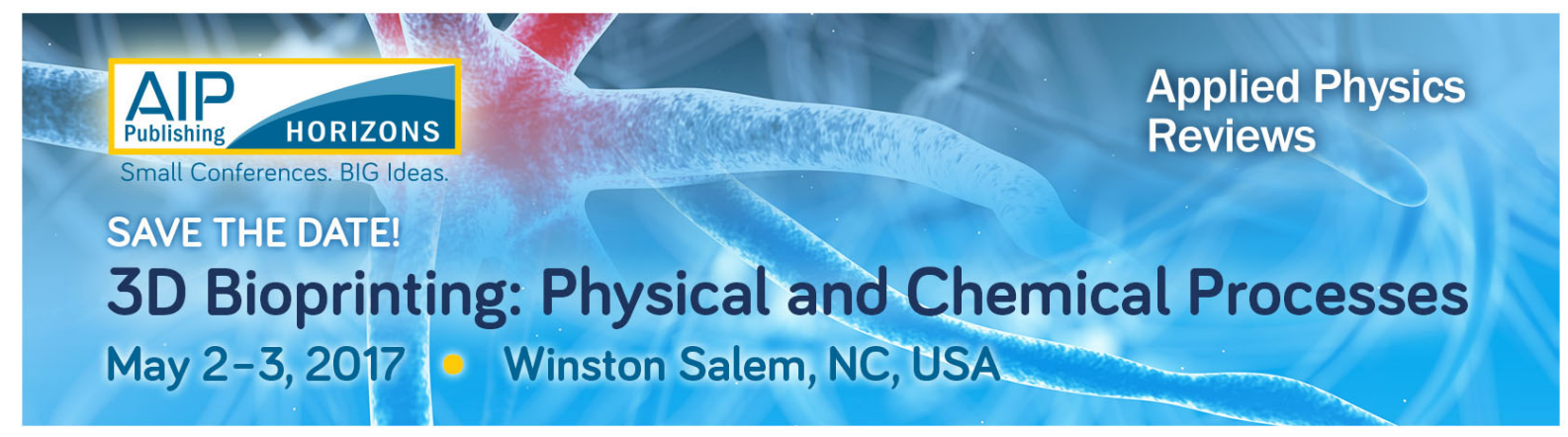




\title{
Characterizing gas flow from aerosol particle injectors
}

\author{
Daniel A. Horke, ${ }^{1,2, a)}$ Nils Roth, ${ }^{1,3}$ Lena Worbs, ${ }^{1}$ and Jochen Küpper ${ }^{1,2,3}$ \\ ${ }^{1}$ Center for Free-Electron Laser Science, DESY, Notkestrasse 85, 22607 Hamburg, Germany \\ ${ }^{2}$ The Hamburg Center for Ultrafast Imaging, Universität Hamburg, Luruper Chaussee 149, 22761 Hamburg, \\ Germany \\ ${ }^{3}$ Department of Physics, Universität Hamburg, Luruper Chaussee 149, 22761 Hamburg, Germany
}

(Received 16 November 2016; accepted 6 March 2017; published online 27 March 2017)

\begin{abstract}
A novel methodology for measuring gas flow from small orifices or nozzles into vacuum is presented. It utilizes a high-intensity femtosecond laser pulse to create a plasma within the gas plume produced by the nozzle, which is imaged by a microscope. Calibration of the imaging system allows for the extraction of absolute number densities. We show detection down to helium densities of $4 \times 10^{16} \mathrm{~cm}^{-3}$ with a spatial resolution of a few micrometers. The technique is used to characterize the gas flow from a convergent-nozzle aerosol injector [Kirian et al., Struct. Dyn. 2, 041717 (2015)] as used in single-particle diffractive imaging experiments at free-electron laser sources. Based on the measured gas-density profile, we estimate the scattering background signal under typical operating conditions of single-particle imaging experiments and estimate that fewer than 50 photons per shot can be expected on the detector. Published by AIP Publishing.
\end{abstract}

[http://dx.doi.org/10.1063/1.4978914]

\section{INTRODUCTION}

The advances of x-ray free-electron lasers (XFELs), which provide intense and short pulses of coherent X-rays, open up new possibilities for imaging of aerosolized particles, and even individual molecules, with atomic spatial resolution. ${ }^{1-4}$ As experiments can be conducted completely in the gas phase and do not require sample immobilization, e.g., cryogenic freezing, XFELs furthermore provide unprecedented capabilities for capturing ultrafast dynamics of isolated systems with femtosecond temporal and picometer spatial resolution. ${ }^{4-7}$ This is enabled by the short and intense $x$-ray pulses available at these facilities, which typically provide pulses with $\sim 1 \mathrm{~mJ}$ pulse energy, $\sim 10 \mathrm{fs}$ pulse duration, and $\sim 100 \mathrm{pm}$ wavelength. This allows the imaging methodology to outrun radiation damage effects in the diffraction before destruction mechanism. ${ }^{8-11}$ Combining many diffraction patterns from reproducible isolated aerosol targets imaged at different orientations should allow one to reconstruct the three-dimensional, atomically resolved structure. ${ }^{12,13}$ In recent years, full 3D reconstruction has been demonstrated and the achieved resolution continuously improved. ${ }^{14-17}$

The advent of these new possibilities for imaging isolated systems in vacuo has prompted the development and improvement of techniques for injecting samples into the interaction region. Using gas-dynamic virtual nozzles $(G D V N s)^{18}$ for producing focused liquid jets enabled the serial femtosecond crystallography (SFX) methodology, ${ }^{19,20}$ allowing the reconstruction of sub-nanometer-resolution structures from micrometer sized crystals. ${ }^{19,21}$ Aerodynamic lenses $^{1,22}$ and convergent-nozzle injectors ${ }^{23}$ are widely used injection techniques to produce focused or collimated

\footnotetext{
a)daniel.horke@cfel.de. URL: https://www.controlled-molecule-imaging.org
}

streams of nano- or micrometer sized particles. They fundamentally rely on a gas flow that interacts with the particles of interest and, through shear and drag forces, produces the desired stream of particles. Typically, helium is used for its relatively small $\mathrm{x}$-ray scattering cross-section. However, since the helium gas density at the interaction point is still many orders of magnitude higher than the sample density, scattering from the focusing gas can make a significant contribution to the recorded background scattering. ${ }^{2,24,25}$ In order to account for this background and to make quantitative predictions and background calibrations, knowledge of the gas density at the interaction point, typically located a few hundred micrometers below the injector tip, is required. $^{23}$

Here, we present a methodology that allows the spatially resolved measurement of gas densities down to $\sim 4$ $\times 10^{16} \mathrm{~cm}^{-3}$ with high spatial and, potentially, temporal resolution. This is achieved by using a high-intensity femtosecond laser pulse to create a plasma within the gas stream, which is then imaged by a microscope objective and camera. The observed intensity of the plasma depends on the local gas pressure in the laser focus. By calibrating the plasma formation and imaging system to known helium pressures, this method allows us to create spatial maps of the gas flow from an injector tip. Compared to previous methods, ${ }^{26,27}$ this approach provides a higher sensitivity, allowing the detection of one order of magnitude lower gas pressures, and it does not rely on interferometric measurements prone to mechanical instabilities. In particular, we characterize a convergent nozzle injector ${ }^{23}$ under typical operation conditions for XFEL single-particle diffractive imaging experiments. Based on the measured gas-density distribution, the x-ray scattering signal expected from this helium background at typical operating parameters of currently available XFEL endstations is calculated. 


\section{EXPERIMENTAL METHOD}

To assess the local gas density at the tip of an aerosol injector, the gas stream was crossed with a focused Ti:Sapphire femtosecond laser beam of sufficient intensity to produce a plasma inside the gas stream. The bright visible glow of this plasma was recorded on a camera. The intensity depended on the laser intensity and the gas density in the interaction volume. By calibrating the imaging system at known gas densities, this allowed us to build up a high-resolution spatial map of local gas densities produced by the injector tip.

A simple sketch of the vacuum and imaging system is shown in Figure 1(a). The vacuum system consisted of two differentially pumped chambers, connected only through the injector tip. The upper chamber, i.e., upstream of the injector, contained a capacitive pressure gauge (Pfeiffer Vacuum CMR361) with an absolute accuracy of $0.2 \%$ independent of gas type, a high-precision leak valve connected to a highpurity helium supply, and a connection to a roughing pump, with the pumping speed controllable through a needle valve. This setup allowed us to maintain a constant pressure during operation of the injector by matching the helium flow into the upper chamber to the gas transmission through the injector aperture. This chamber mimicked the typical nebulization chamber in single-particle imaging experiments. The injector tip, with an $30^{\circ}$ convergence angle and an $111 \mu \mathrm{m}$ orifice, ${ }^{23}$ was mounted on a $6 \mathrm{~mm}$ outer diameter stainless steel tube at

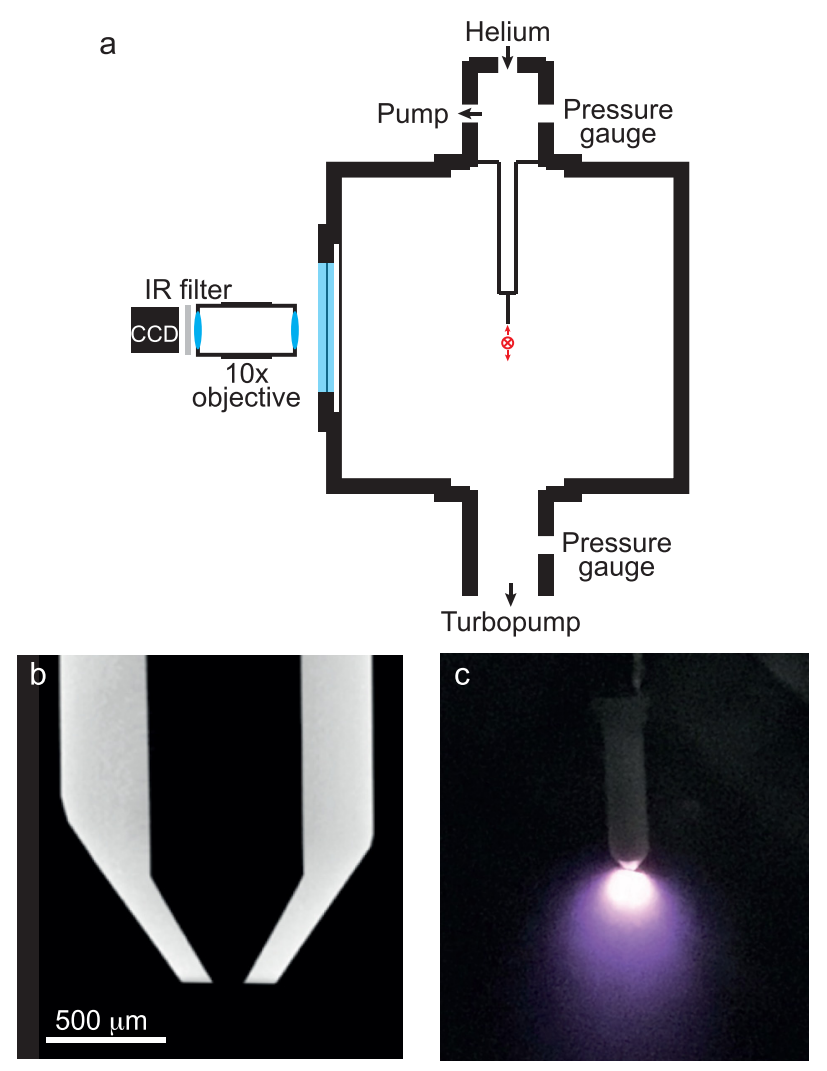

FIG. 1. (a) Sketch of the experimental setup and imaging system. The laser propagates out of the plane of the page (indicated by the red cross) and can be translated in height using a motorized translation stage. (b) X-ray tomogram of a convergent injector tip, c.f. Ref. 23. (c) Picture of the operating injector in the vacuum chamber, showing the produced plasma during helium injection (recorded with a standard mobile phone camera). the bottom of this upper chamber. It was located within the main vacuum chamber as shown in Figure 1(a). This chamber was evacuated by a turbomolecular pump (Pfeiffer Vacuum HiPace 80) and the pressure was monitored through a full-range pressure gauge (Pfeiffer Vacuum PKR361).

The laser passed through the interaction chamber perpendicular to both the gas stream and the imaging axis, as indicated by the red cross in Figure 1. It consisted of pulses from an amplified Ti:Sapphire laser system (Spectra Physics Spitfire ACE) centered around $800 \mathrm{~nm}$, running at $1 \mathrm{kHz}$ repetition rate, and producing $40 \mathrm{fs}$ pulses with $0.7 \mathrm{~mJ}$ per pulse used in the current experiment. The laser beam (waist $\omega \approx 5 \mathrm{~mm}$ ) was focused into the interaction region with a $f=300 \mathrm{~mm}$ plano-convex lens, producing a focal spot size of $50 \mu \mathrm{m}(4 \sigma)$ with a nominal Rayleigh range of $z_{\mathrm{R}} \approx 2.5 \mathrm{~mm}$ and a peak intensity of $8.9 \times 10^{14} \mathrm{~W} / \mathrm{cm}^{2}$. The focusing lens was placed on a 3D translation stage to allow translation of the laser focus in space to ensure overlap with the gas stream within the Rayleigh range and to allow probing of the local gas densities at different distances from the injector nozzle.

The laser-matter interaction was imaged through a standard vacuum viewport with a $10 \times$ long-working-distance microscope objective (Edmund Optics 59-877) that produced an image on a high-sensitivity CMOS camera (Thorlabs DCC 3240M, 10 bit monochrome, $5.3 \mu \mathrm{m}$ pixel size). Residual stray infrared light from the femtosecond laser was blocked using two shortpass filters (Thorlabs FESH0700, OD $>5$ for $\lambda>700 \mathrm{~nm}$ ) mounted between the objective and the camera, and stray light was reduced by mechanically enclosing the optical path. The entire imaging system (objective, filters, and camera) was mounted on a three-dimensional translation stage.

The imaging system was calibrated by recording the plasma-glow intensity when flooding the chamber to a known helium pressure; details are given in the supplementary material. To collect data from the injector produced plasma, the injector tip was installed in the center of the chamber and the upper chamber was pressurized with helium as discussed above. The horizontal laser-injector overlap, i.e., along the imaging axis, was optimized to produce the brightest plasma. Then, the vertical position of the laser was adjusted by translating the focusing lens, such that it passed just below the injector tip. The laser focus was translated downwards in steps of $12.5 \mu \mathrm{m}$ and at every point 20 frames were collected on the camera. The exposure time was adjusted such that the plasma was clearly visible but no saturation occurs. During the subsequent data analysis, the images collected at the same position were averaged and scaled by exposure time.

A pressure map was then produced by comparing all images taken with identical upstream pressures and keeping for every pixel the maximum intensity value occurring in one of the images. This "maximum-intensity-stack" approach was chosen as the images cannot simply be averaged due to the long-lived nature of the plasma glow. This effect is clearly visible in the photograph in Figure 1(c). As the gas is moving rapidly away from the nozzle-due to chocked-flow conditions the speed is probably close to $1000 \mathrm{~m} / \mathrm{s}$ - glowing plasma is observed even several millimeters below the laser excitation. Simply averaging all images collected at different 
positions would therefore have overexposed the lower part of the image (since there is intensity in this part of the image even if the excitation happens far above). Following the combination of images, the pressure for every pixel was retrieved by comparison with the calibration measurements. The plotted isobars were obtained from the experimental data after applying a two-dimensional Gaussian filter with a width $\sigma=4.3 \mu \mathrm{m}$.

\section{RESULTS AND DISCUSSION}

The measured pressure distribution from a convergent nozzle tip operated with 800 mbar of upstream helium is shown in Figure 2. Similar measurements for upstream pressures of 300 mbar and 500 mbar are shown in the supplementary material. During the measurement, the pressure in the main chamber was maintained below $2 \times 10^{-2}$ mbar, ensuring chocked-flow-conditions through the orifice. The topmost measurement was taken around $80 \mu \mathrm{m}$ below the tip; moving the laser further up leads to clipping of the beam and potential damage on the ceramic tip. At distances $\gtrsim 600 \mu \mathrm{m}$ below the tip, the pressure had fallen such that no plasma was observed. The gas pressure was found to decrease strongly with increasing distance from the injector tip, as expected. Due to the acceleration of gas inside the orifice, initially some propensity for the helium to continue along the axial direction is observed, rather than radially isotropic diffusion, resulting in the non-spherical pressure distribution measured. Under typical operating conditions for single-particle diffractive imaging experiments, the interaction region, that is, the crossing point of the x-ray beam with the particle stream, is located $\sim 300 \mu \mathrm{m}$ below the injector tip. At this position, the pressure has already dropped considerably and, for the measurements of 800 mbar upstream pressure, shown in Figure 2, is on the order of 3 mbar.

To quantify the spatial resolution in the produced images, we differentiate between the resolution within the imaging plane, i.e., within the plane of laser illumination, and the resolution parallel to the camera surface. The latter is limited only by the imaging system employed. For the current setup, a single pixel corresponds to $0.86 \mu \mathrm{m}$ (as calibrated with a microscope reticle); however, we estimate the resolution in this plane to be on the order of $2 \mu \mathrm{m}$ due to aberrations and mechanical instabilities. In the direction

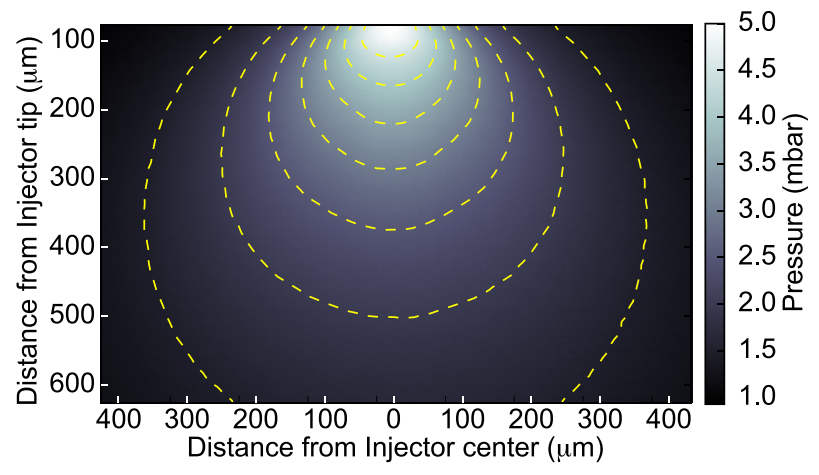

FIG. 2. Pressure map recorded below the tip of a convergent-nozzle injector for an upstream pressure of $800 \mathrm{mbar}$ helium. Dashed yellow lines indicate isobars from 1.5 to 4.5 mbar in 0.5 mbar intervals. perpendicular to the imaging plane, the resolution is not only limited by the depth of focus of the imaging system but also by the focal spot size of the illuminating laser, which is around $50 \mu \mathrm{m}(4 \sigma)$ for the data shown. This is, however, still significantly smaller than the orifice size of the injector, allowing us to image essentially the central slice through the (radially symmetric) pressure distribution.

Helium pressure profiles along both the axial and radial directions are shown in Figure 3, where the measured pressure has been converted into an absolute number density assuming ideal gas behavior. Figure 3(a) shows the axial density distribution along the center line of the injector as a function of distance from the tip for different upstream pressures. The pressure decreases rapidly with the distance from the injector and exhibits approximately a $1 / r^{3}$ dependence, which is shown by the dashed lines in Figure 3(a), as would be expected for an isotropic radial diffusion in 3D. For the production of focused nanoparticle beams, the pressure upstream of the injector is typically in the range of 200-500 mbar, while the particle focus-and hence interaction point - is located a few hundred micrometers downstream the nozzle. ${ }^{23}$ Therefore, the corresponding number densities at the interaction point are typically on the order of $5 \times 10^{16} \mathrm{~cm}^{-3}$. Radial profiles of the helium number density are shown in Figure 3(b), measured at various distances below the injector tip for an upstream pressure of 800 mbar; profiles for further upstream pressures are shown in the
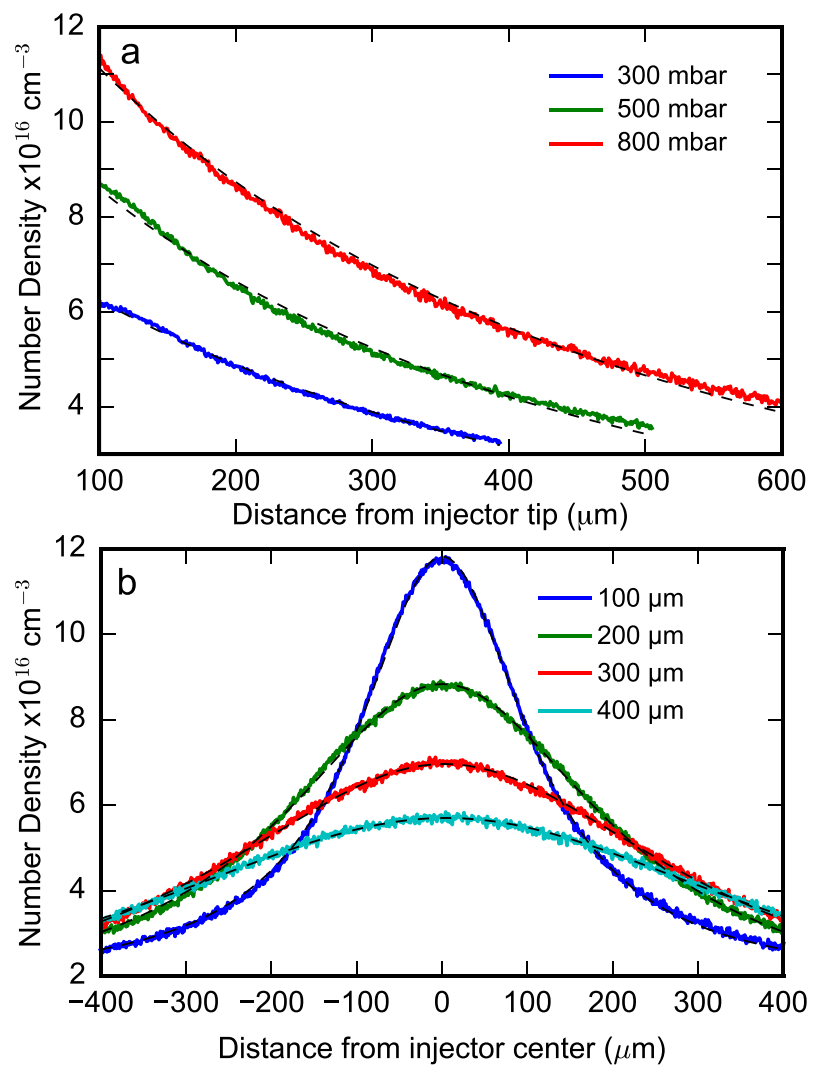

FIG. 3. Gas-density profiles. (a) Axial profile of the number density along the center of the injector as a function of distance from the tip, shown for three different upstream helium pressures. Dashed lines correspond to a $1 / r^{3}$ fit. (b) Radial profiles of the number density across the generated plume for 800 mbar upstream pressure, at four different distances from the injector tip. Dashed lines correspond to a Lorentzian profile fit. 
supplementary material. These distributions were fit to Lorentzian functions, and the good agreement shows that the helium gas-flow has a uniform angular distribution. These results demonstrate that the initially narrow gas plume spreads out radially, leading to a rapid decrease in the absolute density along the center line.

To assess the total scattering signal that can be expected from helium in XFEL based diffraction experiments, one has to take into account not only the interaction point itself, but due to the large Rayleigh length of the XFEL beam, typically several millimeters, one should also take into account the full extent of the helium "cloud" along the x-ray beam, the extent of which is visible from the radial profiles in Figure 3(b). From our spatially resolved measurements, we can assess the average helium density encountered by the XFEL pulse as it travels through the helium cloud, and for 500 mbar upstream pressure, this is $\sim 3.6 \times 10^{16} \mathrm{~cm}^{-3}$, corresponding to the average helium density $300 \mu \mathrm{m}$ below the injector tip as measured within our field of view. Considering the known helium cross sections for elastic (Rayleigh) and inelastic (Compton) scattering and typical operating conditions for the CXI endstation at the Linear Coherent Light Source (LCLS), e.g., $10 \mathrm{keV}$ photon energy and $10^{11}$ photons per pulse, we expect a total of $\sim 500$ scattered $\mathrm{x}$-ray photons per shot due to the helium background gas. Considering an isotropic scattering distribution and a detector opening angle of $60^{\circ}$, this corresponds to $\sim 40$ photons per shot on the detector. We furthermore note that the majority of these photons $(>70 \%)$ originate from inelastic scattering processes and can thus potentially be discriminated against by an energy-resolving detector. ${ }^{28}$

\section{CONCLUSION}

We present a robust and sensitive approach for measuring the spatial distribution of gas flows from nozzles into vacuum. Calibration at known pressures allows the determination of absolute pressures and number densities with a high spatial resolution. With the current setup, the minimum detectable density is on the order of $10^{16} \mathrm{~cm}^{-3}$, around one order of magnitude smaller than with interferometric approaches. ${ }^{26,27}$ The spatial resolution within the imaging plane is around $2 \mu \mathrm{m}$, perpendicular to the imaging plane it is limited by the laser spot size of $50 \mu \mathrm{m}(4 \sigma)$. We also note that this methodology can be further extended to measurements in the time domain, due to the inherently pulsed nature of the laser illumination.

We used this approach to assess the gas flow from a convergent nozzle injector ${ }^{23}$ typically used for single-particle diffractive imaging experiments. We found that at typical operating conditions the gas density in the interaction region is on the order $5 \times 10^{16} \mathrm{~cm}^{-3}$. By evaluating the average gas density encountered by an $\mathrm{x}$-ray pulse as it travels through the gas plume, we estimate that fewer than 500 photons will be scattered. This number could be further reduced by increasing the distance between the injector tip and the interaction region, which could be facilitated through the use of shallower convergence angles within the injector. ${ }^{23}$ Further approaches to reduce the incoherent scattering from helium could incorporate inhomogeneous electric fields to deflect particles of interest out of the helium plume, ${ }^{29,30}$ as has been demonstrated for single molecule scattering experiments at LCLS utilizing supersonic molecular beams. ${ }^{2}$

\section{SUPPLEMENTARY MATERIAL}

See supplementary material for details on the calibration procedure and measured spatial profiles for different injector pressures.

\section{ACKNOWLEDGMENTS}

We gratefully acknowledge support by Salah Awel with the experimental setup, Christian Kruse in an early stage of the experiment, and members of the CFEL Coherent Imaging Division for helpful discussions.

In addition to DESY, this work has been supported by the excellence cluster "The Hamburg Center for Ultrafast Imaging-Structure, Dynamics and Control of Matter at the Atomic Scale" of the Deutsche Forschungsgemeinschaft (CUI, DFG-EXC1074), the Helmholtz Association "Initiative and Networking Fund," and by the European Research Council through the Consolidator Grant COMOTION (ERC-Küpper-614507).

${ }^{1}$ M. J. Bogan, W. H. Benner, S. Boutet, U. Rohner, M. Frank, A. Barty, M. M. Seibert, F. Maia, S. Marchesini, S. Bajt, B. Woods, V. Riot, S. P. HauRiege, M. Svenda, E. Marklund, E. Spiller, J. Hajdu, and H. N. Chapman, "Single particle x-ray diffractive imaging," Nano Lett. 8, 310-316 (2008).

${ }^{2}$ J. Küpper, S. Stern, L. Holmegaard, F. Filsinger, A. Rouzée, A. Rudenko, P. Johnsson, A. V. Martin, M. Adolph, A. Aquila, S. Bajt, A. Barty, C. Bostedt, J. Bozek, C. Caleman, R. Coffee, N. Coppola, T. Delmas, S. Epp, B. Erk, L. Foucar, T. Gorkhover, L. Gumprecht, A. Hartmann, R. Hartmann, G. Hauser, P. Holl, A. Hömke, N. Kimmel, F. Krasniqi, K.-U. Kühnel, J. Maurer, M. Messerschmidt, R. Moshammer, C. Reich, B. Rudek, R. Santra, I. Schlichting, C. Schmidt, S. Schorb, J. Schulz, H. Soltau, J. C. H. Spence, D. Starodub, L. Strüder, J. Thøgersen, M. J. J. Vrakking, G. Weidenspointner, T. A. White, C. Wunderer, G. Meijer, J. Ullrich, H. Stapelfeldt, D. Rolles, and H. N. Chapman, "X-ray diffraction from isolated and strongly aligned gas-phase molecules with a freeelectron laser," Phys. Rev. Lett. 112, 083002 (2014), e-print arXiv:1307.4577 [physics].

${ }^{3}$ J. C. H. Spence and H. N. Chapman, "The birth of a new field," Philos. Trans. R. Soc. B 369, 20130309 (2014).

${ }^{4}$ A. Barty, J. Küpper, and H. N. Chapman, "Molecular imaging using X-ray free-electron lasers," Annu. Rev. Phys. Chem. 64, 415-435 (2013).

${ }^{5}$ K. Pande, C. D. M. Hutchison, G. Groenhof, A. Aquila, J. S. Robinson, J. Tenboer, S. Basu, S. Boutet, D. P. DePonte, M. Liang, T. A. White, N. A. Zatsepin, O. Yefanov, D. Morozov, D. Oberthuer, C. Gati, G. Subramanian, D. James, Y. Zhao, J. Koralek, J. Brayshaw, C. Kupitz, C. Conrad, S. Roy-Chowdhury, J. D. Coe, M. Metz, P. L. Xavier, T. D. Grant, J. E. Koglin, G. Ketawala, R. Fromme, V. Šrajer, R. Henning, J. C. H. Spence, A. Ourmazd, P. Schwander, U. Weierstall, M. Frank, P. Fromme, A. Barty, H. N. Chapman, K. Moffat, J. J. van Thor, and M. Schmidt, "Femtosecond structural dynamics drives the trans/cis isomerization in photoactive yellow protein," Science 352, 725-729 (2016).

${ }^{6}$ T. Gorkhover, S. Schorb, R. Coffee, M. Adolph, L. Foucar, D. Rupp, A. Aquila, J. D. Bozek, S. W. Epp, B. Erk, L. Gumprecht, L. Holmegaard, A. Hartmann, R. Hartmann, G. Hauser, P. Holl, A. Hömke, N. Kimmel, K.-U. Kühnel, P. Johnsson, M. Messerschmidt, C. Reich, A. Rouzeé, B. Rudek, C. Schmidt, J. Schulz, H. Soltau, S. Stern, G. Weidenspointner, B. White, J. Küpper, L. Strüder, I. Schlichting, J. Ullrich, D. Rolles, A. Rudenko, T. Möller, and C. Bostedt, "Femtosecond and nanometre visualization of structural dynamics in superheated nanoparticles," Nat. Photonics 10, 93-97 (2016).

${ }^{7}$ J. M. Glownia, A. Natan, J. P. Cryan, R. Hartsock, M. Kozina, M. P. Minitti, S. Nelson, J. Robinson, T. Sato, T. van Driel, G. Welch, C. Weninger, D. Zhi, and P. H. Bucksbaum, "Self-referenced coherent 
diffraction x-ray movie of angstrom- and femtosecond-scale atomic motion," Phys. Rev. Lett. 117, 153003 (2016), 1608.03039.

${ }^{8}$ R. Neutze, R. Wouts, D. van der Spoel, E. Weckert, and J. Hajdu, "Potential for biomolecular imaging with femtosecond X-ray pulses," Nature 406, 752-757 (2000).

${ }^{9}$ B. Ziaja, H. N. Chapman, R. Fäustlin, S. Hau-Riege, Z. Jurek, A. V. Martin, S. Toleikis, F. Wang, E. Weckert, and R. Santra, "Limitations of coherent diffractive imaging of single objects due to their damage by intense x-ray radiation,” New J. Phys. 14, 115015 (2012).

${ }^{10}$ U. Lorenz, N. M. Kabachnik, E. Weckert, and I. A. Vartanyants, "Impact of ultrafast electronic damage in single-particle $\mathrm{x}$-ray imaging experiments," Phys. Rev. E 86, 051911 (2012).

${ }^{11}$ K. Nass, L. Foucar, T. R. M. Barends, E. Hartmann, S. Botha, R. L. Shoeman, R. B. Doak, R. Alonso-Mori, A. Aquila, S. Bajt, A. Barty, R. Bean, K. R. Beyerlein, M. Bublitz, N. Drachmann, J. Gregersen, H. O. Jönsson, W. Kabsch, S. Kassemeyer, J. E. Koglin, M. Krumrey, D. Mattle, M. Messerschmidt, P. Nissen, L. Reinhard, O. Sitsel, D. Sokaras, G. J. Williams, S. Hau-Riege, N. Timneanu, C. Caleman, H. N. Chapman, S. Boutet, and I. Schlichting, "Indications of radiation damage in ferredoxin microcrystals using high-intensity x-fel beams," J. Synchrotron Radiat. 22, 225-238 (2015)

${ }^{12}$ M. Bergh, G. Huldt, N. Tîmneanu, F. R. N. C. Maia, and J. Hajdu, "Feasibility of imaging living cells at subnanometer resolutions by ultrafast X-ray diffraction,” Quarterly Rev. Biophys. 41, 181-204 (2008).

${ }^{13}$ R. Fung, V. Shneerson, D. Saldin, and A. Ourmazd, "Structure from fleeting illumination of faint spinning objects in flight," Nat. Phys. 5, 64-67 (2009).

${ }^{14}$ M. M. Seibert, T. Ekeberg, F. R. N. C. Maia, M. Svenda, J. Andreasson, O. Jönsson, D. Odić, B. Iwan, A. Rocker, D. Westphal, M. Hantke, D. P. Deponte, A. Barty, J. Schulz, L. Gumprecht, N. Coppola, A. Aquila, M. Liang, T. A. White, A. Martin, C. Caleman, S. Stern, C. Abergel, V. Seltzer, J.-M. Claverie, C. Bostedt, J. D. Bozek, S. Boutet, A. A. Miahnahri, M. Messerschmidt, J. Krzywinski, G. Williams, K. O. Hodgson, M. J. Bogan, C. Y. Hampton, R. G. Sierra, D. Starodub, I. Andersson, S. Bajt, M. Barthelmess, J. C. H. Spence, P. Fromme, U. Weierstall, R. Kirian, M. Hunter, R. B. Doak, S. Marchesini, S. P. HauRiege, M. Frank, R. L. Shoeman, L. Lomb, S. W. Epp, R. Hartmann, D. Rolles, A. Rudenko, C. Schmidt, L. Foucar, N. Kimmel, P. Holl, B. Rudek, B. Erk, A. Hömke, C. Reich, D. Pietschner, G. Weidenspointner, L. Strüder, G. Hauser, H. Gorke, J. Ullrich, I. Schlichting, S. Herrmann, G. Schaller, F. Schopper, H. Soltau, K.-U. Kühnel, R. Andritschke, C.-D. Schröter, F. Krasniqi, M. Bott, S. Schorb, D. Rupp, M. Adolph, T. Gorkhover, H. Hirsemann, G. Potdevin, H. Graafsma, B. Nilsson, H. N. Chapman, and J. Hajdu, "Single mimivirus particles intercepted and imaged with an X-ray laser," Nature 470, 78 (2011).

${ }^{15}$ R. Xu, H. Jiang, C. Song, J. A. Rodriguez, Z. Huang, C.-C. Chen, D. Nam, J. Park, M. Gallagher-Jones, S. Kim, S. Kim, A. Suzuki, Y. Takayama, T. Oroguchi, Y. Takahashi, J. Fan, Y. Zou, T. Hatsui, Y. Inubushi, T. Kameshima, K. Yonekura, K. Tono, T. Togashi, T. Sato, M. Yamamoto, M. Nakasako, M. Yabashi, T. Ishikawa, and J. Miao, "Single-shot threedimensional structure determination of nanocrystals with femtosecond Xray free-electron laser pulses," Nat. Commun. 5, 4061 (2014).

${ }^{16}$ M. F. Hantke, D. Hasse, M. R. N. C. T. Ekeberg, K. John, M. Svenda, N. D. Loh, A. V. Martin, N. Timneanu, L. S. D. van der SchotGijs, G. H. Carlsson, M. Ingelman, J. Andreasson, D. Westphal, M. Liang, F. Stellato, D. P. DePonte, R. Hartmann, N. Kimmel, R. A. Kirian, M. M. Seibert, K. Mühlig, S. Schorb, K. Ferguson, C. Bostedt, S. Carron, J. D. Bozek, D. Rolles, A. Rudenko, S. Epp, H. N. Chapman, A. Barty, J. Hajdu, and I. Andersson, "High-throughput imaging of heterogeneous cell organelles with an X-ray laser," Nat. Photonics 8, 943-949 (2014).

${ }^{17}$ T. Ekeberg, M. Svenda, C. Abergel, F. R. N. C. Maia, V. Seltzer, J.-M. Claverie, M. Hantke, O. Jönsson, C. Nettelblad, G. van der Schot, M. Liang, D. P. Deponte, A. Barty, M. M. Seibert, B. Iwan, I. Andersson, N. D. Loh, A. V. Martin, H. Chapman, C. Bostedt, J. D. Bozek, K. R. Ferguson, J. Krzywinski, S. W. Epp, D. Rolles, A. Rudenko, R. Hartmann, N. Kimmel, and J. Hajdu, "Three-dimensional reconstruction of the giant mimivirus particle with an x-ray free-electron laser," Phys. Rev. Lett. 114, 098102 (2015).

${ }^{18}$ D. P. DePonte, U. Weierstall, K. Schmidt, J. Warner, D. Starodub, J. C. H. Spence, and R. B. Doak, "Gas dynamic virtual nozzle for generation of microscopic droplet streams," J. Phys. D 41, 195505 (2008).

${ }^{19}$ H. N. Chapman, P. Fromme, A. Barty, T. A. White, R. A. Kirian, A. Aquila, M. S. Hunter, J. Schulz, D. P. Deponte, U. Weierstall, R. B. Doak, F. R. N. C. Maia, A. V. Martin, I. Schlichting, L. Lomb, N. Coppola, R. L.
Shoeman, S. W. Epp, R. Hartmann, D. Rolles, A. Rudenko, L. Foucar, N. Kimmel, G. Weidenspointner, P. Holl, M. Liang, M. Barthelmess, C. Caleman, S. Boutet, M. J. Bogan, J. Krzywinski, C. Bostedt, S. Bajt, L. Gumprecht, B. Rudek, B. Erk, C. Schmidt, A. Hömke, C. Reich, D. Pietschner, L. Strüder, G. Hauser, H. Gorke, J. Ullrich, S. Herrmann, G. Schaller, F. Schopper, H. Soltau, K.-U. Kühnel, M. Messerschmidt, J. D. Bozek, S. P. Hau-Riege, M. Frank, C. Y. Hampton, R. G. Sierra, D. Starodub, G. J. Williams, J. Hajdu, N. Timneanu, M. M. Seibert, J. Andreasson, A. Rocker, O. Jönsson, M. Svenda, S. Stern, K. Nass, R. Andritschke, C.-D. Schröter, F. Krasniqi, M. Bott, K. E. Schmidt, X. Wang, I. Grotjohann, J. M. Holton, T. R. M. Barends, R. Neutze, S. Marchesini, R. Fromme, S. Schorb, D. Rupp, M. Adolph, T. Gorkhover, I. Andersson, H. Hirsemann, G. Potdevin, H. Graafsma, B. Nilsson, and J. C. H. Spence, "Femtosecond x-ray protein nanocrystallography," Nature 470, 73 (2011).

${ }^{20}$ I. Schlichting, "Serial femtosecond crystallography: the first five years," IUCrJ 2, 246-255 (2015)

${ }^{21}$ K. Ayyer, O. M. Yefanov, D. Oberthür, S. Roy-Chowdhury, L. Galli, V. Mariani, S. Basu, J. Coe, C. E. Conrad, R. Fromme, A. Schaffer, K. Dörner, D. James, C. Kupitz, M. Metz, G. Nelson, P. L. Xavier, K. R. Beyerlein, M. Schmidt, I. Sarrou, J. C. H. Spence, U. Weierstall, T. A. White, J.-H. Yang, Y. Zhao, M. Liang, A. Aquila, M. S. Hunter, J. S. Robinson, J. E. Koglin, S. Boutet, P. Fromme, A. Barty, and H. N. Chapman, "Macromolecular diffractive imaging using imperfect crystals," Nature 530, 202-206 (2016).

${ }^{22}$ P. Liu, P. J. Ziemann, D. B. Kittelson, and P. H. McMurry, "Generating particle beams of controlled dimensions and divergence: I. theory of particle motion in aerodynamic lenses and nozzle expansions," Aerosol Sci. Technol. 22, 293-313 (1995).

${ }^{23}$ R. A. Kirian, S. Awel, N. Eckerskorn, H. Fleckenstein, M. Wiedorn, L. Adriano, S. Bajt, M. Barthelmess, R. Bean, K. R. Beyerlein, L. M. G. Chavas, M. Domaracky, M. Heymann, D. A. Horke, J. Knoska, M. Metz, A. Morgan, D. Oberthuer, N. Roth, T. Sato, P. L. Xavier, O. Yefanov, A. V. Rode, J. Küpper, and H. N. Chapman, "Simple convergent-nozzle aerosol injector for single-particle diffractive imaging with $\mathrm{x}$-ray free-electron lasers," Struct. Dyn. 2, 041717 (2015).

${ }^{24}$ S. Stern, L. Holmegaard, F. Filsinger, A. Rouzee, A. Rudenko, P. Johnsson, A. V. Martin, A. Barty, C. Bostedt, J. Bozek, R. Coffee, S. Epp, B. Erk, L. Foucar, R. Hartmann, N. Kimmel, K.-U. Kühnel, J. Maurer, M. Messerschmidt, B. Rudek, D. Starodub, J. Thøgersen, G. Weidenspointner, T. A. White, H. Stapelfeldt, D. Rolles, H. N. Chapman, and J. Küpper, "Toward atomic resolution diffractive imaging of isolated molecules with x-ray free-electron lasers," Faraday Discuss. 171, 393 (2014), e-print arXiv:1403.2553 [physics].

${ }^{25}$ S. Awel, R. A. Kirian, M. Wiedorn, K. R. Beyerlein, N. Roth, D. A. Horke, D. Oberthür, J. Knoska, V. Mariani, A. Morgan, L. Adriano, A. Tolstikova, P. L. Xavier, O. Yefanov, A. Aquila, A. Barton, S. R. Chowdhury, M. S. Hunter, D. James, J. Robinson, U. Weierstall, A. V. Rode, J. Küpper, and H. N. Chapman, "Femtosecond x-ray diffraction from an aerosolized beam of protein nanocrystals," J. Appl. Cryst., e-print arXiv:1702.04014 [physics].

${ }^{26}$ G. Golovin, S. Banerjee, J. Zhang, S. Chen, C. Liu, B. Zhao, J. Mills, K. Brown, C. Petersen, and D. Umstadter, "Tomographic imaging of nonsymmetric multicomponent tailored supersonic flows from structured gas nozzles," Appl. Opt. 54, 3491 (2015).

${ }^{27}$ B. Landgraf, M. Schnell, A. Sävert, M. C. Kaluza, and C. Spielmann, "High resolution 3D gas-jet characterization," Rev. Sci. Instrum. 82, 083106 (2011).

${ }^{28}$ L. Strüder, S. Epp, D. Rolles, R. Hartmann, P. Holl, G. Lutz, H. Soltau, R. Eckart, C. Reich, K. Heinzinger, C. Thamm, A. Rudenko, F. Krasniqi, K. Kühnel, C. Bauer, C.-D. Schroeter, R. Moshammer, S. Techert, D. Miessner, M. Porro, O. Haelker, N. Meidinger, N. Kimmel, R. Andritschke, F. Schopper, G. Weidenspointner, A. Ziegler, D. Pietschner, S. Herrmann, U. Pietsch, A. Walenta, W. Leitenberger, C. Bostedt, T. Moeller, D. Rupp, M. Adolph, H. Graafsma, H. Hirsemann, K. Gaertner, R. Richter, L. Foucar, R. L. Shoeman, I. Schlichting, and J. Ullrich, "Large-format, high-speed, x-ray pnccds combined with electron and ion imaging spectrometers in a multipurpose chamber for experiments at 4th generation light sources," Nucl. Instrum. Methods A 614, 483-496 (2010).

${ }^{29}$ F. Filsinger, G. Meijer, H. Stapelfeldt, H. Chapman, and J. Küpper, "Stateand conformer-selected beams of aligned and oriented molecules for ultrafast diffraction studies," Phys. Chem. Chem. Phys. 13, 2076-2087 (2011).

${ }^{30}$ Y.-P. Chang, D. A. Horke, S. Trippel, and J. Küpper, "Spatially-controlled complex molecules and their applications," Int. Rev. Phys. Chem. 34, 557-590 (2015), e-print arXiv:1505.05632 [physics]. 